Note: this is the final authors' draft. All citations should refer to the final published version, in Carl Fox and Joe Saunders (Eds.), Media Ethics, Free Speech, and the Requirements of Democracy (Taylor \& Francis, CRC Press, 2018); https://www.crcpress.com/Media-Ethics-Free-Speechand-the-Requirements-of-Democracy/Fox-Saunders/p/book/9781138571921

\title{
Political Correctness Gone Viral
}

\author{
Waleed Aly and Robert Mark Simpson
}

\begin{abstract}
Communicative practices in online and social media sometimes seem to amplify political conflict, and result in significant harms to people who become the targets of collective outrage. Many complaints that have been made about political correctness in the past, we argue, amount to little more than a veiled expression of resentment over the increasing influence enjoyed by progressive activists. But some complaints about political correctness take on a different complexion, in light of the technologically-driven changes to our communicative practices and political discourse. Given the ways in which they are entangled in these new forms of online communication, well-meaning attempts to police the norms of political correctness may end up contributing to individual wrongs, or to destructive social patterns. In this paper we examine these worries, situate them in a broader sociological context, and offer some tentative proposals about how they might be addressed.
\end{abstract}

\section{Introduction}

The term 'political correctness' refers to a suite of social practices that involve avoiding or policing behaviour - usually speech - that is seen as derogating people in subordinated social groups. The aim of this paper is to critically examine the ramifications of some recent cultural trends that seem to be modifying the ways in which these social practices are carried out.

Debates over political correctness are a staple of the culture wars in contemporary liberal democracies. Since its emergence into mainstream discourse in the 1980s, the term has primarily been a term of abuse. The standard usage of the term is to claim that political correctness has 'gone mad' - that progressives have gone overboard in trying to discourage bad speech, resulting in the blanket condemnation of people who don't hew to progressive ideals, in a way that is inimical to free speech and ideological diversity. We believe that those kinds of complaints are largely wrongheaded. They 
mischaracterise the routine antagonisms of partisan political discourse as an aberrant program of suppression solely carried out by 'the left'. In $\$ 2$ we elaborate on this contention, citing a few other authors who have argued along similar lines.

What we then want to argue, however, is that there are new reasons to worry about political correctness, which differ from these familiar complaints. The policing of political correctness has become interwoven with forms of social intercourse - operating across social media, online media, and traditional broadcast media - that are intensifying the routine antagonisms of political discourse. The consequences of this aren't easy to gauge. But there are prima facie reasons to believe it is harmful for particular individuals, and that it's ultimately likely to advantage the opponents of the ideals that political correctness norms stand for. In $\S 3$ we expand on these claims, and discuss some of the ways in which political correctness norms are involved in the modes of social intercourse we're adverting to. In $\$ 4$ we survey some themes in sociological scholarship that can be used to characterise these new modes of communication, and to contextualise them in relation to some of the larger transformations in the nature of social and political power ushered in by the forces of globalisation. We conclude with some suggestions about how we might address these new tensions around political correctness.

\section{The Standard Script around Political Correctness}

As we say above, the main use of the term 'political correctness' is to express a complaint about how progressives censure behaviour that they see as being involved in oppressive social relations. A predictable script is often followed in conflicts where the language of political correctness is invoked. First, someone in the public eye makes a comment with perceived racist (or sexist, or homophobic) overtones. Second, spokespeople for the cultural left publically condemn the speaker's comment, and in many cases, by extension, the speaker herself. And then third, opponents of the cultural left, making common cause with the speaker, say that free speech is under siege, or that ideological conformity and thought policing are being imposed. The familiar refrain "this is political correctness gone mad!" - encapsulates the third move.

Notice that the claim is nearly always that political correctness has gone mad - not just too far, but positively mad - suggesting a degeneration from some earlier state of sanity. Opposition to political correctness is thus rhetorically packaged-up with some notion of the Good Old Days, before punitive cultural mores prohibited heterodox opinion. These scripts have been set in place for some time now. In a New York Times article in 1990, the lawyer Richard Bernstein observed that the - at that time, still relatively unfamiliar - term, "politically correct"

Has become a sarcastic jibe used by those, conservatives and classical liberals alike, to describe what they see as a growing intolerance, a closing of debate, a pressure to conform to a radical program or risk being accused of a commonly reiterated trio of thought crimes: sexism, racism and homophobia. (Bernstein 1990) 
These remarks do a good job at encapsulating the concerns expressed by the first-wave of the anti-PC brigade in America's pre-Millennial culture wars, including authors like Kimball (1990) and D'Souza (1991). It is striking, though, how well they capture the core themes of anti-PC discourse today, in the 2010s. For instance, Kirsten Powers (2015) suggests that supporters of political correctness think of all opponents of gay marriage as unregenerate bigots - as opposed to reasonable people with traditional attitudes about marriage - and she complains about the left's hounding of those that it views as 'heretics', to silence them and make an example of them for the rest of society. Even though Bernstein casually observed the same kinds of anxieties at work over a quarter of a century ago, Powers frames her concerns as a reaction to the distinctive set of social and political conditions that has emerged in the 2010s.

This is indicative of a general difficulty that anti-PC critics have in positioning their views in relation to the doomsaying of their predecessors. It is harder to take dire prophecies about the slippery slope to left-wing authoritarianism seriously given that there has been similar scare-mongering for decades. Conservative political views are alive and well, after all, and influential in many quarters. There is a point of similarity here with the intergenerational amnesia that occurs when Baby Boomers, once themselves seen as hippy rebels, turn to diagnosing the generational shortcomings of Millennials. And this similarity isn't purely a coincidence. For some authors, anti-PC bromides go hand-in-hand with the pathologisation of Millennial youths. One example of this is Greg Lukianoff and Jonathan Haidt's article "The coddling of the American mind" (2015), which critiques ideas and practices that are central to contemporary progressive activism in higher education, like 'microaggressions', and the use of 'trigger warnings'. Lukianoff and Haidt claim that the special vulnerabilities of young adults raised in the 1990s are resulting in a breakdown of the traditional university ethos of free inquiry, and giving birth to a corrosive culture of victimhood. But despite the time-stamping of these observations, Lukianoff and Haidt's ideas have much in common with those in the 1987 book that their title alludes to, Allan Bloom's The Closing of the American Mind. Where Bloom lamented the modern university's "homogenization of American culture", which, on his view, was geared towards the avoidance of all confrontation (1987, p. 35), Lukianoff and Haidt now sound similar warnings about efforts to 'scrub campuses clean' of ideas that make others uncomfortable. The telling resemblances aren't only in the views being advanced, but in the argumentative styles being employed. Like Bloom, Lukianoff and Haidt offer a mix of horror stories about people being attacked for saying the wrong thing, speculation on the flaws of the young people driving the trends, and forecasts about the authoritarian misery that the trends are leading to.

Just as the shape of anti-PC discourse has been set in place for a long time, there is, correspondingly, a stock repertoire of moves used in counterarguments against antiPC discourse. The critical point emphasised by many defenders of political correctness is simply that all sides of politics - conservatives and progressives alike, and all their sub-groups and branches - engage in aggressive public critique of their opponents, while also, where possible, using informal methods of censure to undermine the visibility and effectiveness of their opponents' messages. According to this line of analysis, 
there were never any Good Old Days during which political discourse was unencumbered by punitive cultural mores. The ideal which lies at the heart of American First Amendment doctrine - of public debate being "uninhibited, robust, and wide-open" - has always been a utopian aspiration rather than a social reality. ${ }^{1}$ All that has changed, in contexts where political correctness norms have gained some ascendancy, are the facts about which mores are subscribed to by which people, and about which infringements of social mores can therefore be effectively dissuaded using informal censure.

John Wilson made this point nicely 20 years ago, coining the term 'Conservative Correctness' to signal the patent fact that conservatives are also known to hound people for professing verboten opinions - for example, in the United States, anti-Israel, or proCommunist views (Wilson 1995, pp. 31ff). The milder form of this line of argument simply draws attention to this evident symmetry, like in Nat Hentoff's (1992) insistence that both sides of politics routinely try to censor each other. But there are more provocative variations on this kind of critique. Robert Sparrow (2002) argues that proponents of anti-PC discourse aren't merely being obtuse in failing to acknowledge the ubiquity of cultural contestation around political speech, that they are, rather, engaged in an intentional program of obfuscation aimed at discrediting legitimate progressive critique of conservative policy. By this line of reasoning, what opponents of political correctness are really demanding isn't just the right to speak in ways progressives dislike, but to be free from criticism or resistance when they do. Stanley Fish (1994) takes another tack, suggesting that the entire discourse around political correctness comes with an implicit suggestion that it's possible to address social issues in a way that is above or outside politics, and insisting that this isn't merely false, but a pernicious masquerade. At the extremities we find critics like Judith Butler (1998) saying that censorship is everywhere, that some things are always unsayable - that this is a condition of linguistic communication itself: to impose an order on our thoughts that renders some things articulable and others not - and that complaints about censorship tend to obscure the ways in which speakers are always already censored.

One needn't venture to such extremes, though, in order to make the point that's essential for our purposes. What's good for the goose is good for the gander. As Paul Krugman (2012) says, "right-wing political correctness... has lots of power and money behind it", such that "even talking about the wealthy brings angry denunciations" and "even talking about inequality is class warfare". In light of this, it seems inaccurate and tendentious to claim that there is something specially coercive in progressives trying to shout down their political opponents. One may lament the fact that this is how political discourse typically functions, in modern liberal societies, and argue that greater effort should be made, on all sides of politics, to resist the impulse towards aggressive censure and outrage-mongering as communicative strategies. Our point is that this isn't some novel, nefarious trend that has been created by leftist cunning, or made possible by the emotional fragility of babyish Millennials. This is politics as usual. 


\section{Cyber-Mobbing and Public Shaming}

It is important to keep all of the above in mind when we encounter fresh complaints about the supposed scourge of political correctness. Much of what animates these complaints is resentment over the fact that friends of progressive ideals have built up a greater capacity to censure, pressure, and influence public discourse in a way that the establishment - big business, entrenched political interests, traditional print and broadcast media, and the custodians of traditional views on sex and sexuality (including the church) - have been able to do all along. However, having emphasised these misgivings about how appeals to political correctness often function, we now want to argue that some current-day anxieties about the spectre of political correctness, bespeak reasonable concerns - by which we mean: concerns that aren't just self-serving, biased, or obtuse - about the destructive potential of the methods through which the censuring, pressuring, and influencing of public discourse are now being carried out.

When the first wave of widespread anti-PC sentiment bubbled up in the late 1980s, social media didn't yet exist, traditional news media companies were relatively stable and profitable, 'mobbing' was a method of coercion confined to workplaces, and noone had ever uttered the word 'clickbait'. Today, complex socio-political ecosystems have been spawned by the rapid technological transformation of communication technology and the media, and in particular, by social media's erosion of the old boundaries separating everyday communication technology from the prestige media. In the wake of this transformation it has become relatively easy for mobs of anonymous people to, in a loosely coordinated manner, harass, threaten, and publically shame people they never meet, but whose misdeeds have been broadcast online and disseminated in turn. What is interesting about these episodes isn't merely their harmful potential, but also their disproportionality and chaotic unpredictability. An ill-expressed comment on Twitter will often sink without a trace, like a momentary faux pas at a social gathering, but in some cases it will unexpectedly escalate and result in the tweeter being publically disgraced.

The worries arising due to these phenomena are importantly unlike the gripes that drive old-fashioned anti-PC bellyaching. Of course there was never any prelapsarian era in which public political discourse was free from people attempting to shout down their opponents and take them down a peg. That kind of conflict can be seen as a natural (if regrettable) element of democratic discourse. So to be clear, the sense in which political correctness is running amok, today, doesn't lie in the mere fact that hostile contention surrounds our communication. It lies in the amplification of hostilities, and the unleashing of volatile social forces through new modes of social intercourse that are global in reach, tolerant of anonymity, near-instantaneous, and often blasé about (or positively opposed to) customary liberal attitudes about privacy.

The phenomena that we're adverting to here aren't obscure. Jon Ronson's book So You've Been Publically Shamed (2015) was a bestselling investigation of these trends, focusing on accounts of people whose lives were thrown into turmoil by online backlashes in response to their perceived cyber-sins. One of the more notorious examples 
of this, discussed by Ronson, is the case of Justine Sacco. In 2013, Sacco, a communications director, tweeted the message "Going to Africa. Hope I don't get AIDS. Just kidding. I'm white" before boarding a flight from New York to Cape Town. When her flight landed half a day later, Sacco's clumsy attempt at edgy humour, addressed to her coterie of Twitter followers (but visible to the wider world), was the top-trending topic on Twitter internationally. And this level of attention, combined with the common interpretation of her tweet - that she was being derogatory towards black people, rather than making an ironic comment on white privilege - resulted in her being sacked, denounced on news websites around the world, and receiving thousands of abusive messages (Ronson 2012). Similar cases are discussed in Jennifer Jacquet's book Is Shame Necessary? (2015), and while Jacquet wants to identify some positive potential in public shaming tactics as a way to advocate for reforms in corporate practices, she recognises, like Ronson, that shaming is a tool that can be wielded against individuals to devastating effect.

Anecdotes like the Sacco case could be multiplied at length, but by themselves they don't reveal much about the prevalence of the phenomena in question, nor do they offer an overarching perspective on how what we're seeing today is different in kind from the methods of informal social coercion that were available pre-internet. In making the case that something new and pernicious is afoot, when it comes to online shaming and cyber-mobs, we can go beyond individual anecdotes to make general observations about the institutional changes in news media and communications technology over the last decade. First, social media networks that allow people to easily broadcast their thoughts to the whole world are now ubiquitous, whereas as recently as 15 years ago they were a niche product. Second, traditional news media - particularly broadcast media - has acquired a habit of mining social media for stories, so that conflicts playing out in a social media context have a chance of receiving mass attention beyond the immediate circle of participants. It is hard to identify a historical precedent for this process in which random chatter - including spats between strangers, and off-hand remarks to no one in particular - can be rapidly vacuumed-up into the production of mass media. Third, traditional print and broadcast media are locked in competition with online media for audience share. And fourth, styles of communication that originated in online contexts - like clickbait journalism - are increasingly involved in journalistic and editorial practices at large, as media companies migrate away from print circulation to mobile content-delivery platforms.

The point of these observations is to note that while there have always been rancorous political quarrels, bullying demagogues, and volatility around mob-like behaviour, the communication landscape of today allows for wider (often anonymous) participation in this, while speeding everything up, and equipping us with gadgets that keep us in constant contact, so that a consciousness of the punitive cultural mores of different groups casts a shadow over every moment of online communication. We say that technological developments allow these things to occur, but that's probably understating things. Political conflicts and outrages have been tactically commercialised by media organisations, with notional affiliations to both progressive and conservative audiences. There are many people employed right now, in jobs that didn't even exist at the 
turn of the millennium, whose professional success hinges on how effectively they can manufacture outrages and controversies to be shared via Twitter and Facebook.

One might view the changes that we're describing as a democratising development, and therefore welcome news for the progressive ideals associated with political correctness. That seems too sanguine, though, for at least two reasons. First, as the Sacco case suggests, even well-meaning attempts by progressives to police ideals of anti-racism, anti-sexism (etc.) can contribute to significant harms because of the volatile social dynamics created by new technology and media. Second, these dynamics can be exploited by speakers and groups who are hostile to socially marginalised people. The powers that have been unleased can be used to attack radical progressives, neo-Nazis, and everyone in between. The Gamergate controversy, in which several prominent women in the video game industry faced vicious online harassment over their criticism of the industry's prejudices against women, is just one of many recent cases in which the punitive enforcement of cultural ideals - at the intersection of online communication, social media, and traditional media - was used to attack advocates of a progressive agenda (see Massinari 2015). Given the content of the attacks, of course no one was inclined to describe this episode as an instance of 'political correctness gone mad'. But the style of the social pressure involved in Gamergate was structurally similar to that involved in the online enforcement of political correctness norms today. It was ostensibly a case that involved people being harassed and vilified by others, who were largely unknown to them, over their violation of - or opposition to - social mores that those participating in the harassment wanted to uphold.

In sum, then, even if we grant that there is some sort of democratisation occurring in these evolving modes of social discourse, its impact on the relation between dominant and subordinated social groups is at best ambiguous. The power of the angry, looselycoordinated, anonymous swarm can be used to exert pressure on people who express and enact prejudicial views. But equally, this kind of power can be - and sometimes is - used to threaten women, ethnic minorities, and other dissident voices who engage in social critique in public forums, only to find themselves targeted in the cross-hairs of the reactionary blogosphere. And insofar as these episodes lead to a wider degeneration of political discourse, the implications of that seem unlikely to aid progressive political causes. When people on all sides of politics are at risk of becoming the targets of mass outrage, it seems like the politics of hatred, xenophobia, and tradition has a competitive advantage over a politics of hope, inclusion, and social transformation.

\section{The Fragmentation of Social and Discursive Power}

We have suggested that developments in media and communications systems have made it possible for people with relatively minimal resources and institutionalised social power to nevertheless have a serious impact on the policing of public discourse, and to impose significant costs and penalties upon individuals who transgress de facto social norms. 
In this section we situate these observations in a wider sociological context. Developments in communications technology are aligned with transformations in politics and economics, which have complicated and sometimes inverted structures of social power. These changes are a focal point in the work of contemporary sociologists seeking a new theoretical conception of power, which makes sense of the influence exerted by the apparently disempowered. Zygmunt Bauman's account of 'post-Panoptical' power is a foray in this direction. "What mattered in the Panopticon" according to Bauman, "was that the people in charge were assumed always to 'be there', nearby, in the controlling tower" (Bauman 2000, p.11). By contrast, he says

What matters in post-Panoptical power-relations is that the people operating the levers of power on which the fate of the less volatile partners in the relationship depends can at any moment escape beyond reach - into sheer inaccessibility. (Ibid, p. 11)

What Bauman has in mind in this characterisation is exemplified in the position of super-rich individuals who aren't affected by the material limitations that constrained the wealth and resources of their predecessors. Whereas "Rockefeller might have wished to make his factories, railroads and oilrigs big and bulky and own them for a long, long time to come", Bauman says, someone like Bill Gates "feels no regret when parting with possessions in which he took pride yesterday" (Ibid, pp. 13-14). Rockefeller's power and prestige were grounded in material strongholds - and were vulnerable to material forms of contestation: theft, sit-ins, and vandalism - in a way that Gates' power isn't. Instead, Gates' power is "exterritorial, no longer bound, not even slowed down, by the resistance of space". The type of power that Gates enjoys, according to Bauman, "augurs the end of the era of mutual engagement" (Ibid, p. 11).

This disengagement is epitomised in global capital's frictionless flow towards tax havens, and its slipping out of the control of the state, leaving the state to compete for the affection of businesses by deregulating labour and creating tax havens. But the key point here isn't about the power of capital - which still, after all, aligns with traditional social hierarchies - it is about the nature of the power that capital is wielding. It is a power that, in John Urry's terms "is all about speed, lightness, distance, the weightless, [and] the global" (2002, p. 60). The crucial change is in the decoupling of social power from the modes of coercive force that the state monopolises. Violent coercion is still a kind of direct engagement. The newly disengaged power is available to a wider range of actors; "elites as well as those resisting elites" (Ibid, p. 60).

We can view the social changes discussed in $\$ 3$ in that light. It is becoming easier for people to be harmed by attackers with whom they never directly interact. The power at work in these cases is neither the monopolistic power of the state, nor the oligarchic power of the media baron, but the power of the swarm: geographically unbounded, fluid, spontaneous, and leaderless - and for all these reasons, difficult to contain. These features indicate some common ground between social media activists and exponents of sub-state military tactics; guerrillas, insurgents, and terrorists. In different ways, both kinds of actors partake of "the power of the powerless to inflict... harm upon institutions of imperial power, especially those buildings, institutions and people that symbolize the intense condensation of imperial power" (Urry 2003, p. 
130). This comparison risks exaggerating the stakes of social media, but the correspondences are there all the same. While episodes of leader-less cyber-harassment are likely to be most damaging when they're targeting everyday people, as in the Sacco case, they can also harm the interests of public figures, whose off-hand remarks can be quickly seized upon by social media users and characterised to the wider world in a scandalised, sensationalistic mood. These episodes occur alongside a growing stream of news stories in which traditional media reports on, and amplifies, commentary originating on social media. Social media thus exerts a kind of power over traditional media, "exerting a gravity-effect, with almost the whole world 'watching' and being seduced into being "watched'" (Urry 2002, p. 61). At the same time, though, traditional media institutions themselves become watched in a new way. Casually misogynistic banter on television, and other blasé public expressions of privilege, now become

Captured, represented, transported, marketed and generalized elsewhere. They get carried along the scapes and flows of the emerging global world, mobilizing ideas, people, images, moneys and technologies to potentially everywhere. (Urry 2003, p. 80)

The 2016 scandal in Australia around the sexist banter of media personality Eddie McGuire demonstrates these features. The scandal only broke a week after the offending remarks were broadcast on commercial radio, after being dissected in a then-obscure online podcast. ${ }^{2}$ In short, McGuire's words only registered widely after they had slipped across the boundary of a radio broadcast and flowed into the digital world, where they were disseminated through social media, so that a diverse set of audiences could digest, deconstruct, and denounce them. Scandals like these become mediated in unpredictable ways, and cannot be controlled by the people involved in them, regardless of the traditional forms of social influence they might enjoy.

These phenomena require a new sociological frame of understanding. Here Bauman is helpful again, with his notion of liquid modernity. He defines this by drawing a contrast with the age of 'solid modernity', as articulated in the canons of classical sociology. On the classical understanding, the nation-state is a geographically contained entity, overseeing a determinate, hierarchical social order, where social interactions occur on terms of "mutual dependency, mutual engagement, production and servicing of mutually binding and durable bonds" (Bauman 2001, p. 139, emphases in original). In a world like this, the society of each nation-state can be represented as a discrete organism, in which each component is hierarchically positioned according to its function. ${ }^{3}$ Under conditions of liquid modernity these structures dissolve. Public discourse becomes unconstrained by national boundaries, as exemplified in national newspapers being usurped by global online media companies. Social and political movements move online and become globalised in a similar way. These changes occur incrementally, while at times being accelerated by political crises relating to the environment, the economy, and security. The organic structure of society is superseded by a causal order that exhibits fluid dynamics. Its constituent elements flow around one another - sometimes reacting, sometimes mixing together - without necessarily settling into a stable solution (Urry 2003, pp. 104-05). Political leaders, state agencies, companies, and other classically-conceived actors become entities through which things flow: information, ideas, money, images, and influence. 
The government or the media corporation can still be a significant node in the causal systems through which the currents of power flow, but they are diminished in their ability to channel those currents of power. We find ourselves moving towards a system with "no global society or single centre of global power" (Ibid, p. 93). This is true even of the world's most conventionally powerful political actor. The US government still retains "exceptional centrality within most of the networks that criss-cross the globe" (Ibid, p. 45). But this centrality is unlike the hegemonic control of earlier superpowers, because it fails to result in any kind of inexorable, imperially-driven movement towards a global culture or a single, coherent global society under American patronage, or any other sort of centralised patronage (Bauman 2001, p. 138).

It is within this kind of disrupted order that political correctness norms and progressive language-policing operate today. Progressive activists prosecuting their agenda on social media don't exist straightforwardly above or below traditional institutions of power. The power dynamics around political correctness aren't captured by this spatial logic, because they emerge out of a system in which different social levels exert influence on each other without settling into any neat organisation. System effects still occur, but not in a structurally predictable way. ${ }^{4}$ Media companies, much like the nation-state, can still retain certain trappings of old-fashioned privilege. They have wealth, infrastructure, and patronage networks, and by virtue of these they retain a capacity to frame agendas and amplify messages. But any hegemonic control they might have once enjoyed is complicated by what we might call the microhegemonies that arise in social media enclaves. In these enclaves, the conventionally disempowered can sometimes call the shots. The power of the media corporation interacts with the fluid power of the conventionally disempowered, just as the nation-state influences the global order while being affected by global powers beyond its control. These forms of power are intertwined, in that

There are parallel, irreversible and mutually interdependent processes by which globalization-deepens-localization-deepens-globalization and so on... with huge flows of 'resources' moving backwards and forwards between the two... The global-local develops in a symbiotic, unstable and irreversible set of relationships, in which each gets transformed through billions of worldwide iterations dynamically evolving over time. (Urry 2003, p. 84)

The blurring of local and global forces described above is sometimes called "glocalisation". ${ }^{5}$ Roland Robertson introduces this term in the social sciences to push back against the simple assumption that globalisation "overrides locality", leaving in its wake only "local assertions against globalizing trends" (Robertson 1995, pp. 26, 29, emphasis in original). As an example of why this assumption is an oversimplification of what globalisation does, consider a minority community within a state, some of whose members' experiences overlap with other minority groups, and who accordingly develop relations of political solidarity with them on the basis of these "commonality conditions" (Glasford and Calcagno 2012). For Robertson, this gives rise to a "glocal" form of identity, borne of the experience of straddling and moving between the local and global aspects of social experience. It is these kinds of 'glocalised' identities that sound strongly in the discursive policing of conventional privilege. Where online microhegemonies manage to police the discourse of the conventionally powerful, this is 
partly because they are simultaneously 'macro'. They may be governed by less powerful communities within a nation, but they're also anchored in accessible global movements (e.g. those centred around gender, race, and sexuality) whose influence is sometimes stronger - and more flexible in its borderless reach - than the structures of social influence at work within the nation.

The new sociology of complexity and liquidity that we're describing underscores the already-evident limitations in state-centric free speech theory. If these new forms of power mean that the state is becoming less hegemonic - and indeed, is vulnerable to 'liquid' forms of power - then free speech theory must renew its attention to extra-legal forms of censorship and silencing. Whereas, under solid modernity, legal punishment was the most threatening source of tyrannical power, under liquid modernity the tyranny of the swarm looms large as well.

The milieu that we're describing may thus call to mind Mill's famous remarks about the tyranny of the majority. Classical free speech discourse is a product of the age of 'solid modernity', which partly explains why it tends to be preoccupied with censorship by the state, and less concerned with the ways in which informal social censure can be used to silence or persecute. This preoccupation has always been suspect, in its downplaying of the repressive power of non-state actors. ${ }^{6}$ (Indeed, anti-PC discourse tacitly recognises this, given that its usual focal point is discourse-policing carried out by private individuals.) In any case, despite being a key influence in the formation of this theoretical tradition, Mill's own writing shows a subtle appreciation of the ways in which informal social censure can be used to silence and persecute. He begins in On Liberty by acknowledging that democratic self-rule is a welcome form of progress from rule by autocratic elites. His worry, however, is that this development threatens to suppress individuality and originality. In a democracy the people rule over themselves, but this means they gain the ability to form majoritarian mobs to subjugate supporters of eccentric and unorthodox views, to the detriment of everyone's long-term interests. When a democratically self-governed society imposes majoritarian attitudes in this manner, according to Mill

It practises a social tyranny more formidable than many kinds of political oppression, since, though not usually upheld by such extreme penalties, it leaves fewer means of escape, penetrating much more deeply into the details of life, and enslaving the soul itself. (Mill 2001, p. 9)

What is needed in response to this, Mill says, is a way of protecting people in their convictions that goes beyond a mere aversion to the authoritarian domination of the many by the few. We need durable safeguards against society's tendency to "prevent the formation, of any individuality not in harmony with its ways" and to compel "all characters to fashion themselves upon the model of its own" (Ibid, p. 9). Mill's recommended framework to this end - liberal individualism, underwritten by the harm principle - has largely been absorbed into the background conditions of today's conflicts, and so by itself it probably cannot be expected to fix things. But his account of social tyranny is informative nonetheless. It helps to sensitise us to the crushing sense of exposure that afflicts the person who speaks in public forums, while knowing that she's at risk of being mobbed by people eager to threaten and vilify her. The advice 
frequently given to authors publishing online work on political issues - "never read the comments section!" - is indicative of how that pressure gets a purchase on people today. And although we should be careful not to assert any simplistic equivalences in giving an account of how these pressures are experienced on different sides of politics, it's at least worth noting that this sense of being hounded into silence shows up in the reports both of people condemned for their infringement of political correctness norms, and also people harassed over their public promotion of the kind of progressive ideals that underpin political correctness norms.

Mill says that exposure to this kind of pressure 'enslaves the soul itself. It is a grandiose way of stating the point, but there is probably a grain of truth in it all the same. A version of this idea resurfaces in work by Nagel (1998), who suggests that the unravelling of privacy norms in political life not only drives capable people away from the public sphere, but also erodes our commitment to the principle that people should be allowed to process their anxieties away from other people's surveilling gaze. Some version of this idea is also suggested in relational accounts of autonomy developed by contemporary feminist philosophers (e.g. Mackenzie and Stoljar 2000). If one's identity as an autonomous being is formed and sustained in one's social relations, then the threat of mass public censure doesn't just constrain the expression of one's self, it also has the potential to jeopardise one's status as an autonomous individual.

However one fleshes out the claim, exactly, the thing that Mill was worried about is clear enough. An important part of a person's mental life and self-image becomes impaired when living under conditions that penalise her for failing to conform to the prevailing social codes and cultural orthodoxies. Many authors have identified the ways in which these pressures arise for members of particular social groups; Mill's observations about the mental costs imposed by the tyranny of the majority aren't news to the oppressed. What has changed for all of us, though, in light of the social-technological transformations that we have been describing here and in the previous section, is that the tyranny of the majority has splintered out into a plurality of potential tyrannies. There are no simple majorities in a glocalised world, and the power that comes with 'following the crowd' no longer follows a predictable trajectory. In the unruly ecosystem of online and social media, there are new ways to use informal censure to attack privileged individuals and defenders of traditional centres of power. But informal censure can equally be used to attack members of oppressed groups and progressive activists.

\section{Implications}

Our suggestion, then, is that the routine antagonisms of political discourse are becoming more volatile, as online communication transforms our social customs, and that this effect is symptomatic of broader technological and sociological changes that are reorganising established power structures. We have argued that the policing of political correctness norms has become intertwined with new and destructive modes of online social intercourse, and we have suggested that these modes of intercourse are 
something to be resisted, rather than embraced. But what would resistance involve, exactly? And where does this leave political correctness?

We cannot magically disentangle the ideals that underlie political correctness from the negative aspects of the communicative systems in which those ideals are nowadays expressed. But obviously this doesn't mean that we should abandon the ideals, either. What follows, if anything, is that we may have reasons to adjust the norms that express those ideals, or modify the way in which we try to police those norms. But nothing in our analysis suggests that we should take a negative view of political correctness norms as such, or the intentions that gave rise to them in the social milieu that preceded the era of online media. Richard Rorty is an example of someone who has a similar perspective on political correctness. He says that the academy "encouraging students to be what mocking neoconservatives call 'politically correct' has made our country a far better place" (Rorty 1998, p. 82). But at the same time he sees some major downsides to this progress. Political correctness norms reflect the post-1960s progressive intellectual's preoccupation with the unmasking of identity-based discrimination and prejudice. But these preoccupations displaced the pre-1960s American progressive's prioritisation of reformist social policy aimed first and foremost at combatting poverty. And according to Rorty, this shift contributed to the dissolution of the coalition that defined mid-century American progressive politics, between the labour movement and liberal intellectuals (Ibid, pp. 83ff.).

Rorty's hope was that there might be a way to relax the preoccupation with political correctness, and rebuild a broad progressive coalition focused on combating material injustice, but without losing sight of the urgency of opposing identity-based prejudice. In a similar vein, the appropriate response to our concerns isn't to downplay the importance of opposing identity-based prejudice, but to find ways to enact this opposition that aren't so integrally involved in - and potentially distorted by - the sometimes toxic mood of social media. Needless to say there are many organisations and individuals who aren't merely focused on scoring points in online culture wars, but who are working in direct, practical ways to achieve social change and address material injustices, and who are also unambiguously opposed to identity-based prejudice.

Those actors can serve as a source of inspiration and guidance about how to take the values that animate political correctness offline, in a world that seems to treat online participation as compulsory. The very choice to try to enact one's politics offline - instead of engaging in purely discursive or symbolic forms of politicking - seems like a good place to start.

Of course, it is easy to say that we shouldn't join in with counterproductive modes of online communication. It is presumably possible, in principle, for the policing of political correctness norms on social media to be done judiciously, without devolving into the destructive dynamics that we see in cases of online mobbing and cyber-harassment. But it's part of the nature of these phenomena that the people involved in them don't see themselves as part of a mob. As Kathryn Norlock says, "the magnitude of online shaming exceeds what its authors intend or even believe to be true" (2017, p. 189). People engaged in these practices will tend to think of themselves as merely 
expressing their feelings, figuring out their political views, talking with friends, criticising unjust practices, or simply passing time. It may be possible, however, for these insular perspectives to be effectively challenged. Norlock suggests that we might be able to nurture a recognition of the ways in which online communication can slip out of our reach, and become more destructive than we intended. If we are going to participate in social media, she says, "we should do so with concerted attention to the uncontrollable aspects of the tool we employ, and the effects that, though we may not intend them, we are complicit in inducing in others or... bringing about" (Ibid, p. 195). For those who feel compelled to carry on prosecuting political correctness norms on social media, paying attention to these concerns seems like a minimal condition for doing so in a measured and socially responsible manner.

These remarks suggest that we are looking for individually-applicable solutions to a problem whose causes are structural. If communication has been technologically transformed in a way that aggravates the hostility of political discourse, this probably isn't something that can repaired just by individuals trying harder to be virtuous. On the other hand, taking a more structural perspective on how to address these concerns hardly makes things easier. Short of trying to shut down social media networks en masse, or some other drastic, benighted, authoritarian intervention, agencies of the state have a limited ability to govern the forces that shape communicative practices in this arena. In theory the state could adopt a long-term civic education strategy, trying to equip its citizens with the tools they need to navigate the hazards of online communication in a more productive way. But this seems optimistic to say the least.

In the absence of dramatic structural reforms, the best we can hope for may be the cultivation of a patchwork of sites in which debate is allowed to be genuine and robust, while also being cordoned-off from the surveillance and outrage-mongering that so easily escalates into cyber-mobbing. Mediators of discursive spaces - in the academy, the media, and the arts - might try to sponsor novel communicative forums, which seek to free their participants from the self-censoring anxiety that their speech could trigger an online backlash, in something like the way that brainstorming exercises are meant to free people from the self-censoring worry that their ideas may be regarded as stupid. But these innovations face a limiting constraint from the outset. They would only succeed in their aspirations to the extent that they break the lines of communication between speakers and the audiences they would have once hoped to reach.

If we sound a little pessimistic about how to respond to these challenges, that is no accident. It is easy for liberals, or anyone subscribing to Enlightenment ideals, to cling onto a faith in the edifying potential of communication. We can easily find ourselves believing that under the right conditions, provided that it is facilitated in the right way, open conversation and good faith political discourse will help us to understand each other and figure out reasonable compromises wherever they are necessary. This kind of perspective shows up in a more theoretically nuanced guise in the work of many political philosophers - Jürgen Habermas (1991), Joshua Cohen (1997), and Seana Shiffrin (2014), to name just a few contemporary examples. And of course it is 
reflected in the familiar idea from free speech discourse, that the best remedy to harmful speech is more speech. But this faith may start to be shaken when one reflects on the dysfunctionality of online communication today - the triumph of misinformation, the amplification of partisan hostility, and the spread of online mobs and cyber-harassment.

One might be lured, then, towards a kind of radical alternative perspective. One may start to think that the acrimony that's unleashed, as political discourse is transformed by online communication, isn't an aberration that derails our underlying ability to respectfully disagree with our ideological opponents. Rather, so one might say, it is a revelation of something that the editorial supervision of traditional media frequently masked, namely, our patent inability to deal with the conflicts and disagreements that divide our societies. Instead of trying to wriggle out of these communicative dynamics that have the potential to hurt themselves and their allies as much as their opponents, proponents of political correctness norms may come to view political discourse as a battleground, plain and simple, and try to make better use of the weapons which define the battle, in order to win it. The aggravation of hostilities is just what we need, they might say. Appealing to ideals of decorum and 'fair-play' in the communicative sphere ultimately makes life easier for unregenerate bigots. Anxious hand-wringing about the victims of cyber-mobs is just a kind of bleeding-heart squeamishness. Intolerance must be met with intolerance. These sorts of remarks represent a significant strand of progressive thought, and from time to time they receive a careful and sophisticated defence (e.g. Marcuse 1965).

Embracing this way of thinking would be a gamble. If the attempt to trigger mass outrage in the censuring of one's political opponents is deliberately taken up by all sides, as a tactical weapon, then traditionally dominant social classes may ultimately prove to be better at wielding that weapon - and gaining strategic advantages in the changing social order - than their opponents. Subordinated groups may want to embrace the volatility that engulfs online political discourse, hoping that amid the chaos, their efforts to silence their opponents will be more effective than their opponents' efforts to silence them. But in a context where nationalistic rhetoric and theatrical fearmongering can be effectively used to rally mass support for reactionary agendas, that may indeed be a case of political correctness run amok. When it comes to online communication, opposing rhetorical extremes seem to exist in a state of symbiosis. As our remarks above suggest, there may be no obvious and straightforward ways to break out of this symbiosis. But attempting to break out of it may still be the lesser of two evils.

\section{References}

Bauman, Z. (1998) On glocalization: or globalization for some, localization for some others. Thesis Eleven 54 (1), pp. 37-49.

(2000) Liquid Modernity. Cambridge: Polity Press.

(2001) The great war of recognition. Theory, Culture $\mathcal{E}$ Society 18 (2), pp. 137-150.

Bernstein, R. (1990) The rising hegemony of the politically correct. New York Times, $28^{\text {th }}$ October 1990, www.nytimes.com/1990/10/28/weekinreview/ideas-trends-the-rising-hegemony-of-the-politicallycorrect. 
Bloom, A. (1987) The Closing of the American Mind: How Higher Education Has Failed Democracy and Impov erished the Souls of Today's Students. New York: Simon \& Schuster.

Brison, S. J. (1998) The autonomy defense of free speech. Ethics 108 (2), pp. 312-339.

Butler, J. (1998) Ruled out: vocabularies of the censor. In Censorship and Silencing: Practices of Cultural Regulation, ed. R. Post, pp. 247-60. Los Angeles: Getty Research Institute for the History of Art and the Humanities.

Cohen, J. (1997) Deliberation and democratic legitimacy. In Deliberative Democracy: Essays on Reason and Politics, eds. J. Bohman and W. Rehg, pp. 67-92. Cambridge MA: MIT Press.

Creeber, G. (2004) 'Hideously white': British television, glocalization, and national identity. Television $\mathcal{E}$ New Media 5 (1), pp. 27-39.

D'Souza, D. (1991) Illiberal Education: The Politics of Race and Sex on Campus. New York: The Free Press.

Durkheim, E. (1982) The Rules of Sociological Method and Selected Texts on Sociology and Its Method, trans. W. D. Halls. New York: The Free Press.

Fish, S. (1994) There's No Such Thing as Free Speech: And It's a Good Thing, Too. Oxford: Oxford University Press.

Fiss, O. M. (1996) The Irony of Free Speech. Cambridge MA: Harvard University Press.

Glasford, D. E. and Calcagno, J. (2012) The conflict of harmony: intergroup contact, commonality and political solidarity between minority groups. Journal of Experimental Social Psychology 48 (1), pp. 323 328.

Habermas, J. (1991) The Structural Transformation of the Public Sphere: An Inquiry into a Category of Bourgeois Society. Cambridge MA: MIT Press.

Hentoff, N. (1992) Free Speech for Me but Not for Thee: How the American Left and Right Relentlessly Censor Each Other. New York: HarperCollins.

Jacquet, J. (2015) Is Shame Necessary? New Uses for an Old Tool. New York: Pantheon.

Kimball, R. (1990) Tenured Radicals: How Politics has Corrupted our Higher Education. New York: Harper \& Row.

Krugman, P. (2012) The new political correctness. New York Times, $26^{\text {th }}$ May 2012, krugman.blogs.nytimes.com/2012/05/26/the-new-political-correctness/.

Lewin, R. (1993) Complexity: Life on the Edge of Chaos. London: Dent.

Lukianoff, G. and Haidt, J. (2015) The coddling of the American mind. The Atlantic, September 2015, www.theatlantic.com/magazine/archive/2015/09/the-coddling-of-the-american-mind/399356/.

Mackenzie, C. and Stoljar, N. (2000) Introduction: refiguring autonomy. In Relational Autonomy: Feminist Perspectives on Autonomy, Agency and the Social Self, eds. C. Mackenzie and N. Stoljar, pp. 3-34. New York: Oxford University Press.

Marcuse, H. (1965) Repressive tolerance. In A Critique of Pure Tolerance. Boston: Beacon Press.

Massinari, A. (2017) Gamergate and the fappening: how Reddit's algorithm, governance, and culture support toxic technocultures. New Media $\mathcal{E}$ Society 19 (3), pp. 329-346.

Mill, J. S. (2001) On Liberty. Ontario: Batoche. [Originally published 1859.]

Nagel, T. (1998) Concealment and exposure. Philosophy Eु Public Affairs 27 (1), pp. 3-30.

Nash, E. J. (2018) Non-State enemies of freedom - Orwell's blind spot? In 1984 and Philosophy, eds. E. Di Nucci and S. Storrie. Chicago: Open Court Press.

Norlock, K. J. (2017) Online shaming. Social Philosophy Today 33, pp. 187-197.

Powers, K. (2015) The Silencing: How the Left is Killing Free Speech. Washington D. C.: Regnery Publishing.

Robertson, R. (1995) Glocalization: time-space and homogeneity-heterogeneity. In Global Modernities, eds. M. Featherstone, S. Lash, and R. Robertson, pp. 25-44. London: Sage.

Ronson, J. (2012) How one stupid tweet blew up Justine Sacco's life. New York Times, $12^{\text {th }}$ February 2012, www.nytimes.com/2015/02/15/magazine/how-one-stupid-tweet-ruined-justine-saccoslife.html?_r=0. 
(2015) So You've Been Publicly Shamed. New York: Riverhead.

Rorty, R. (1998) Achieving our Country: The William E. Massey Sr. Lectures in the History of American Civilization. Cambridge MA: Harvard University Press.

Roudometof, V. (2005) Transnationalism, cosmopolitanism and glocalization. Current Sociology 53 (1), pp. $113-135$.

Shiffrin, S. V. (2014) Speech Matters: On Lying, Morality, and the Law. Princeton: Princeton University Press.

Sparrow, R. (2002) Talking sense about political correctness. Journal of Australian Studies 73 (1), pp. 119. 133.

Swyngedouw, E. (1997) Neither global nor local: 'glocalization' and the politics of scale. In Spaces of Globalization: Reasserting the Power of the Local, ed. K. R. Cox, pp. 137-166. New York: Guilford.

Urry, J. (2002) The global complexities of September 11th. Theory, Culture EF Society 19 (1), pp. 57-69.

(2003) Global Complexity. Cambridge: Polity Press.

Wilson, J. K. (1995) The Myth of Political Correctness: The Conservative Attack on Higher Education. Durham: Duke University Press.

\footnotetext{
${ }^{1}$ The phrase is borrowed from Justice Brennan's opinion for the majority in New York Times Co. v. Sullivan (376 U.S. 254, 1964), in which he speaks of America's "profound national commitment to the principle that debate on public issues should be uninhibited, robust, and wide-open".

${ }^{2}$ Namely, Episode \#14 of the Outer Sanctum Podcast, "an unconventional all-female footy [i.e. Australian Football League, or AFL] podcast that features six passionate fans... who focus on stories and voices rarely heard around the great game of AFL" (see outersanctum.com.au/about/).

${ }^{3}$ As in, for example, Durkheim (1982). This 'organism' analogy appears throughout this text and is an extension of his positivist ambition of achieving "the scientific study of social phenomena" (Ibid, p. 31).

${ }^{4}$ In Roger Lewin's words, the interaction of the individual components gives rise to "some kind of global property... something you couldn't have predicted from what you know of the component parts", and this then "feeds back to influence the behaviour of the individuals... that produced it" (Lewin 1993, pp. 12-13).

${ }^{5}$ The term is employed throughout Urry (2003); and it also serves as a structuring concept in work by Swyngedouw (1997), Bauman (1998), and Roudometof (2005). For discussions of glocalisation in relation to the media specifically, see for instance Creeber (2004).

${ }^{6}$ In defence of this point, see for instance Fiss (1996), Brison (1998), or more recently, Nash (2018).
} 